\title{
Orange nodules in the skin of cultured turbot Scophthalmus maximus containing lipofuscin-like pigments
}

\author{
J. Lamas ${ }^{1, *}$, B. Novoa ${ }^{2}$, A. Figueras ${ }^{2}$ \\ 'Biología Celular, Departamento de Biología Fundamental, Facultad de Biología, Universidad de Santiago de Compostela, \\ E-15706 Santiago de Compostela, Spain \\ ${ }^{2}$ Instituto de Investigaciones Marinas CSIC, Eduardo Cabello 6, E-36208 Vigo, Spain
}

\begin{abstract}
Orange nodules of different sizes ( 1 to $4 \mathrm{~cm}$ in diameter) were observed on the skin and fins of cultured turbot Scophthalmus maximus (L.). These nodules were located mainly in the dermis and hypodermis and were composed of numerous aggregates of pigment-laden macrophages surrounded by a mixture of epithelioid cells and spindle-shaped cells. The epithelioid cells were very large, had eosinophilic cytoplasm and contained a large nucleus formed by 1 or more lobules and prominent nucleoli. Occasional multinucleate cells were also observed. Affected turbot also displayed melanophore hyperplasia in some patches of the skin. Histochemical studies suggested that the orange pigments were lipofuscin-like substances. Affected turbot showed glomerulonephritis and dilated renal tubules. The presence of pigments in the epithelial cells of the intestinal mucosa and in the hepatocytes suggests that these substances or their precursors were included in the food and that affected turbot were unable to metabolize them.
\end{abstract}

KEY WORDS: Pigments Epithelıoid cells · Granuloma Turbot · Nutrition

\section{INTRODUCTION}

Turbot Scophthalmus maximus is a marine flatfish belonging to the family Bothidae which is extensively cultured in Galicia (northwest Spain). The high economic importance of the turbot culture has resulted in a number of studies dealing with the health status of this fish, and numerous pathological problems related to viruses and bacteria (Novoa et al. 1991. Toranzo et al. 1993, 1994), parasites (Fernández-Puentes 1991) and tumors (Lamas et al. 1990) have been described. However, there is a lack of studies on the nutritional requirements of this species, and it may be that many of the diseases are related to nutritional problems which predispose the fish to suffer stress and infections. Farmed fish are frequently fed strong diets very rich in fatty acids and proteins which are not always

•E-mail: bfsuso@usc.es properly balanced and which, in consequence, are deleterious to their health.

The presence of individuals of different sizes with characteristic orange nodules on the skin has been observed among the turbot of 2 fish farms. Affected fish also displayed lesions in several internal organs. Fish with these symptoms eventually died. The present study suggests that the orange skin nodules and the internal lesions may be induced by some components of the diet.

\section{MATERIALS AND METHODS}

Fish. Twenty-five turbot (15 with orange skin nodules) were collected from the 2 fish farms in 1993 and processed for virological, bacteriological and histological examination. The size of affected fish ranged between $200 \mathrm{~g}$ and $3 \mathrm{~kg}$. Fish were killed by cervical section before necropsy. 
Microbiology. Bacteriological and virological studies were carried out following standard procedures (Thoesen 1994). No viruses were isolated from these fish. The bacteriological analysis revealed the presence of Vibrio spp. in some of the affected turbot.

Light microscopy. The dissected nodules as well as samples of the spleen, kidney, liver and intestine of affected and non-affected turbot were fixed in 10\% buffered formalin for light microscope studies. For normal histological examination, samples were embedded in paraffin wax and sectioned at $5 \mu \mathrm{m}$, and slides were stained with haematoxylin and eosin (H\&E) and with van Gieson's method. For histochemistry, tissues were frozen and sectioned on a cryostat (Reichert-Jung 1800). Demonstration of carotenoid pigments was carried out with concentrated sulphuric acid following the method of Ishikawa et al. (1978). The solubility of pigments in either acetone, ethanolchloroform $(2: 1)$, toluene or dichloroethane was also examined. Cryostat sections were also stained with periodic acid-Schiff (PAS), toluidine blue, the MassonFontana method for melanin (Pearse 1985), Sudan IV for lipids at $60^{\circ} \mathrm{C}$, Perls' Prussian blue for iron, and the long Ziehl-Neelsen method for acid-fast substances (Pearse 1985).

\section{RESULTS}

\section{Gross pathology}

Large orange nodules of different sizes (1 to $4 \mathrm{~cm}$ in diameter) were observed in the skin and fins of affected turbot (Fig. 1). The nodules were soft with a smooth surface and were located on both pigmented and white sides of the fish. Black hyperpigmentation was observed surrounding the nodule or in small patches in other parts of the skin (Fig 1). Fish with external nodules frequently displayed an internal reddish colouration which mainly affected the liver and intestine. No other gross pathology was observed in internal organs. The prevalence of fish having orange skin nodules was approximately 1 affected turbot per $10^{3}$ fish.

Fish with no external nodules displayed a normal appearance externally and internally.

\section{Histopathology}

Turbot without nodules on the skin did not show any histological alterations in the organs studied, with the exception of fatty liver, a condition which is considered to be 'normal' in cultured turbot.

\section{Nodules}

All the nodules examined microscopically showed similar histological features. The lesion was mainly located in the hypodermis and in the stratum compactum of the dermis but with invasion of the upper stratum spongiosum and the underlying skeletal muscle. The nodule was composed of a mixture of large epithelioid and smaller spindle-shaped cells which enclosed numerous aggregates of pigmentladen macrophages varying in size (Fig. 2). Some of the epithelioid cells were very large, reaching $90 \mu \mathrm{m}$ in

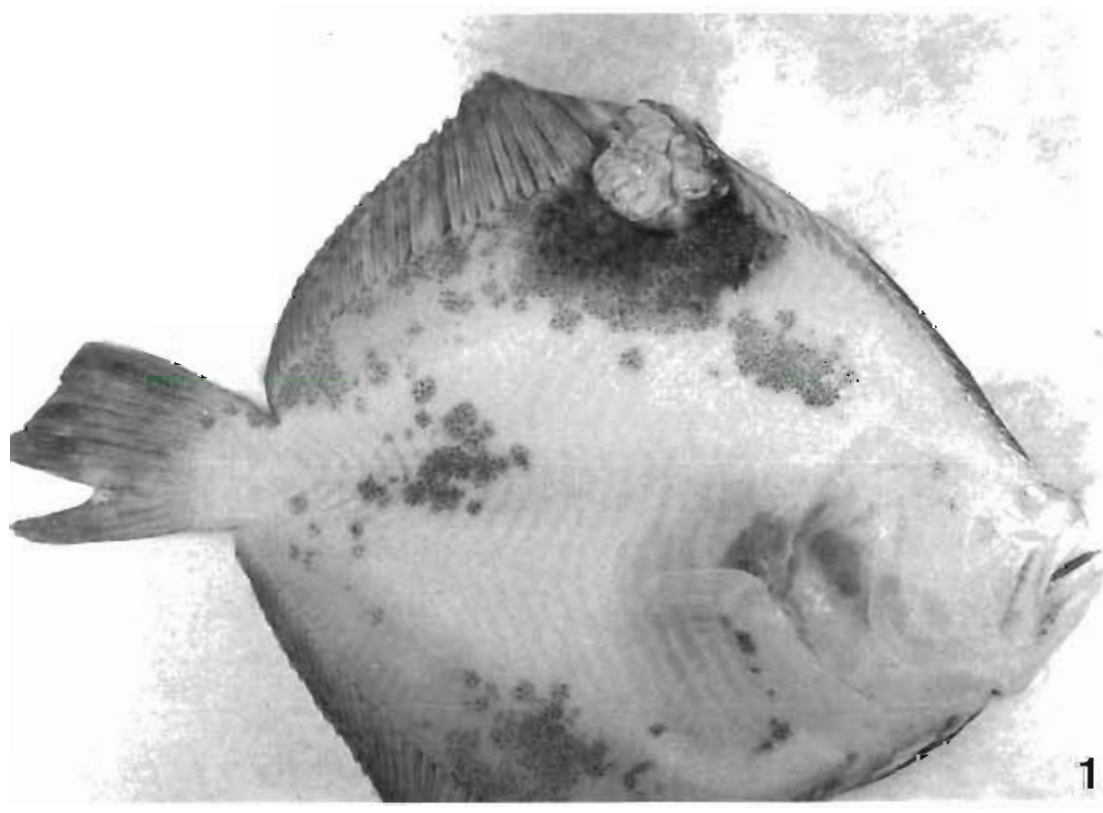

Fig. 1 Scophthalmus maximus. White side of an affected turbot showing an orange nodule surrounded by a hyperpigmented area. Small hyperpigmented areas are also observed in other parts of 


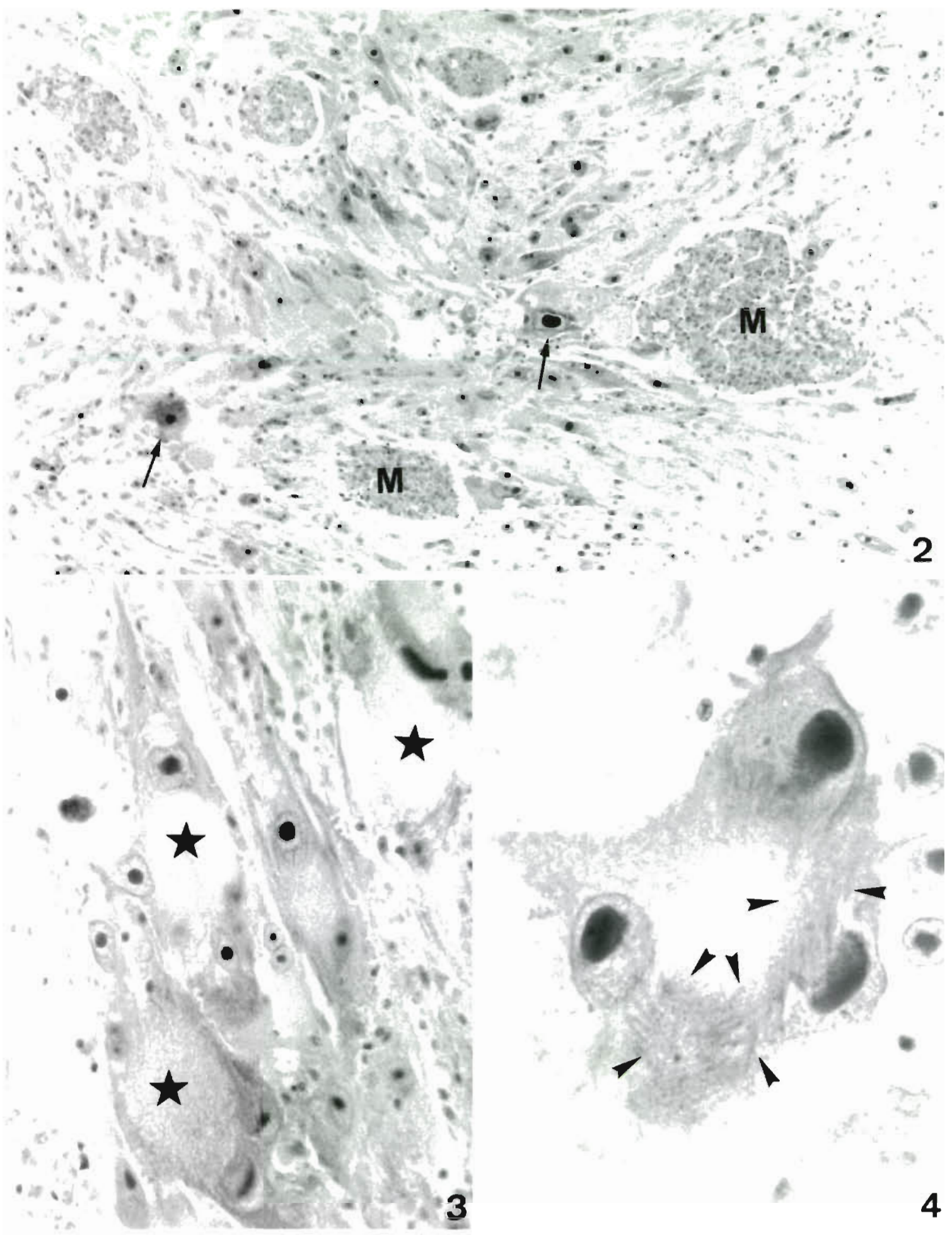

Figs. 2 to 4. Scophthalmus maximus. Fig. 2. Section through the nodule. Numerous aggregates of pigment-laden macrophages (M) and a mixture of spindle-shaped and epithelioid cells, some of them with a large nucleus and prominent nucleolus, are observed (arrows). H\&E, $\times 170$. Fig. 3 . Section through the nodule showing epithelioid cells with large nucleus and finely granular eosinophilic cytoplasm (stars). H\&E, $\times 470$. Fig. 4. Epithelioid cell showing a pleomorphic nucleus containing several lobules joined by poorly delimited bridges (arrowheads). H\&E, $\times 1180$ 
diameter, rounded to fusiform in shape, with abundant eosinophilic cytoplasm containing fine granular material which showed a Sudan IV and moderate PAS positivity (Figs. $3 \& 5$ ). Most of these cells contained 1 very large and pleomorphic nucleus with 1 or more prominent nucleoli. This nucleus was often bilobulated or multilobulated with the nuclear lobules joined by fine bridges (Figs. 4 \& 5). Some of these very large cells were multinucleate. In some parts of the lesion the spindle cells were relatively scarce and lay between the clusters of large epithelioid cells. In other areas, the spindle cells were more abundant and only a few scattered epithelioid cells were found between them. In the periphery, near the stratum spongiosum, the lesion was frequently invaded by many large melanophores. The vascularization of the nodule was usually poor, especially the central area, and the inflammatory reaction was scarce or absent. No capsule was observed surrounding the lesion.

Large epithelioid cells with small macrophage aggregates and melanophore hyperplasia were also observed in the stratum spongiosum of the dermis. These macrophages contained a mixture of orange pigment and melanin (Fig. 6). The overlying epidermis was also often infiltrated with large melanophores or with pigment-laden macrophages. Small areas of the underlying skeletal muscle were also affected. Aggregates of pigment-laden macrophages and epithelioid cells were observed between the muscle fibres, which were usually detached from the sarcolemma (Fig 7)

The histochemical studies showed that the orange pigments were not dissolved out with the organic solvents and remained even after embedding in paraffin, and were not reactive to concentrated sulphuric acid. These pigments stained with PAS and with Sudan IV. However, these substances stained negative with Perls' Prussian blue, Masson-Fontana and Ziehl-Neelsen.

Spleen

The spleen of affected turbot showed a marked increase in the size and number of melanomacrophage centres. Abundant pigment-laden macrophages were also observed in the red pulp and in the ellipsoids.

\section{Kidney}

Pigment-like material was observed in the endothelium of kidney sinusoids and in abundant macrophages located in the sinusoids or between the haematopoietic tissue. The melanomacrophage centres were also highly developed and increased in size and number. The nephron was seriously affected. Affected turbot showed a diffuse glomerulonephritis characterized by an increased cellularity of the glomerular tuft. The Bowman's space was always very dilated and often containing pigment-like material. The parietal layer of the Bowman's capsule, composed of squamous cells with flattened nuclei in normal turbot, was constituted of a layer of cuboidal cells with basal nuclei (Fig. 8), similar to neck cells, probably as a consequence of the displacement of these neck cells. Renal tubules were very dilated and contained variable amounts of pigment-like material in the lumen (Fig. 8). The majority of these tubules had flattened and intensely vacuolated epithelial celis. Renal tubules with epithelial cells containing pigment-like deposits were also frequently observed

Liver

The hepatocytes of affected turbot accumulated large amounts of pigment-like material, usually mixed with normal fat. Pigment-laden macrophages were also observed in the sinusoids or forming aggregates between the hepatocytes (Fig. 9).

\section{Intestine}

All affected turbot had abundant pigment-like material within the epithelial cells of intestinal mucosa. Pigment-laden macrophages appeared frequently infiltrating the epithelium, lamina propria and submucosa (Fig. 10).

\section{DISCUSSION}

Based on the external colouration, the orange lesions described in this study resembled chromatophoromas. However, the histochemical analysis demonstrated that the orange pigmented substances were not extracted with fat solvents and were not reactive to sulphuric acid, suggesting that lipophores were not implicated in the nodule.

The pigmented substances were insoluble in fat solvents, remained in the tissue after embedding in paraffin, and stained with PAS and Sudan IV. However, they were acid-fast and haemosiderin-negative and did not reduce silver solutions. Based on these observations and following the dichotomous table for the analysis of lipids (Gabe 1976), the pigmented substances observed in the lesion are lipofuscin-like pigments.

The main histological features of the nodules are probably an expression of a granulomatous reaction to 


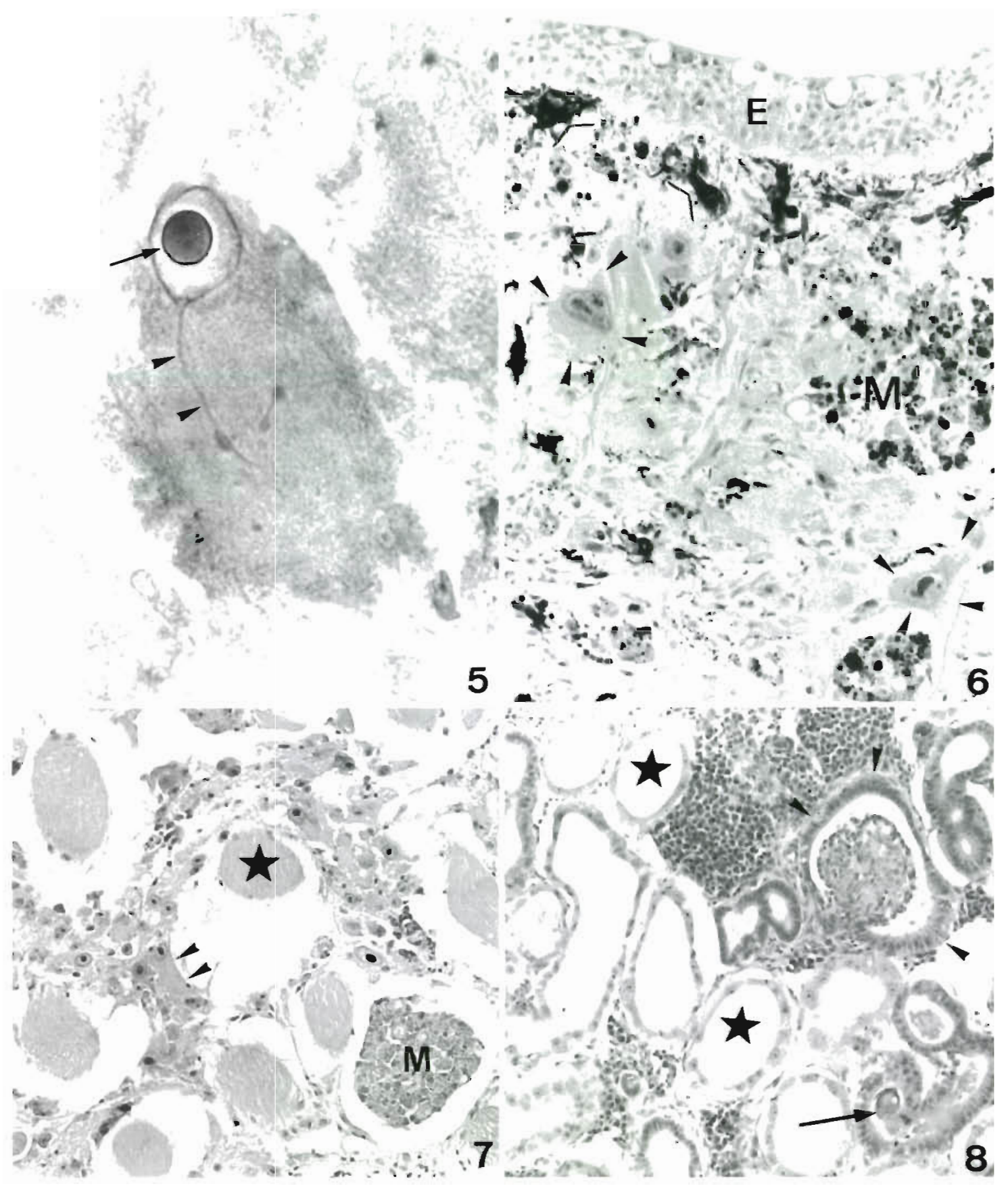

Figs. 5 to 8. Scophthalmus maximus. Fig. 5. Epithelioid cell showing a nuclear lobe with a prominent nucleolus (arrow) and a nuclear extension (arrowheads) which is probably joined to other nuclear lobules not included in the picture. H\&E $\times 1180$. Fig. 6 . Section through the upper dermis and the epidermis (E). Note the presence of aggregates of pigment-laden macrophages ( $M$ ) also containing abundant phagocytosed melanin granules. Very large cells (arrowheads) are observed in the dermis, as are melanophores (white arrows). H\&E, $\times 190$. Fig. 7. Section through the underlying muscle. Aggregates of pigment-laden macrophages $(M)$ and epithelioid cells (arrowheads) accumulated between the muscle fibres (star) which are frequently atrophied. H\&E, $\times 250$. Fig. 8. Section through the kidney. Tubules (stars) were very dilated and some of them showed deposits of pigments (arrow). Hypercellularity of the glomerular tuft, dilatation of the Bowman's space and a thicked Bowman's capsule (arrowheads) are observed. H\&E, $\times 180$ 


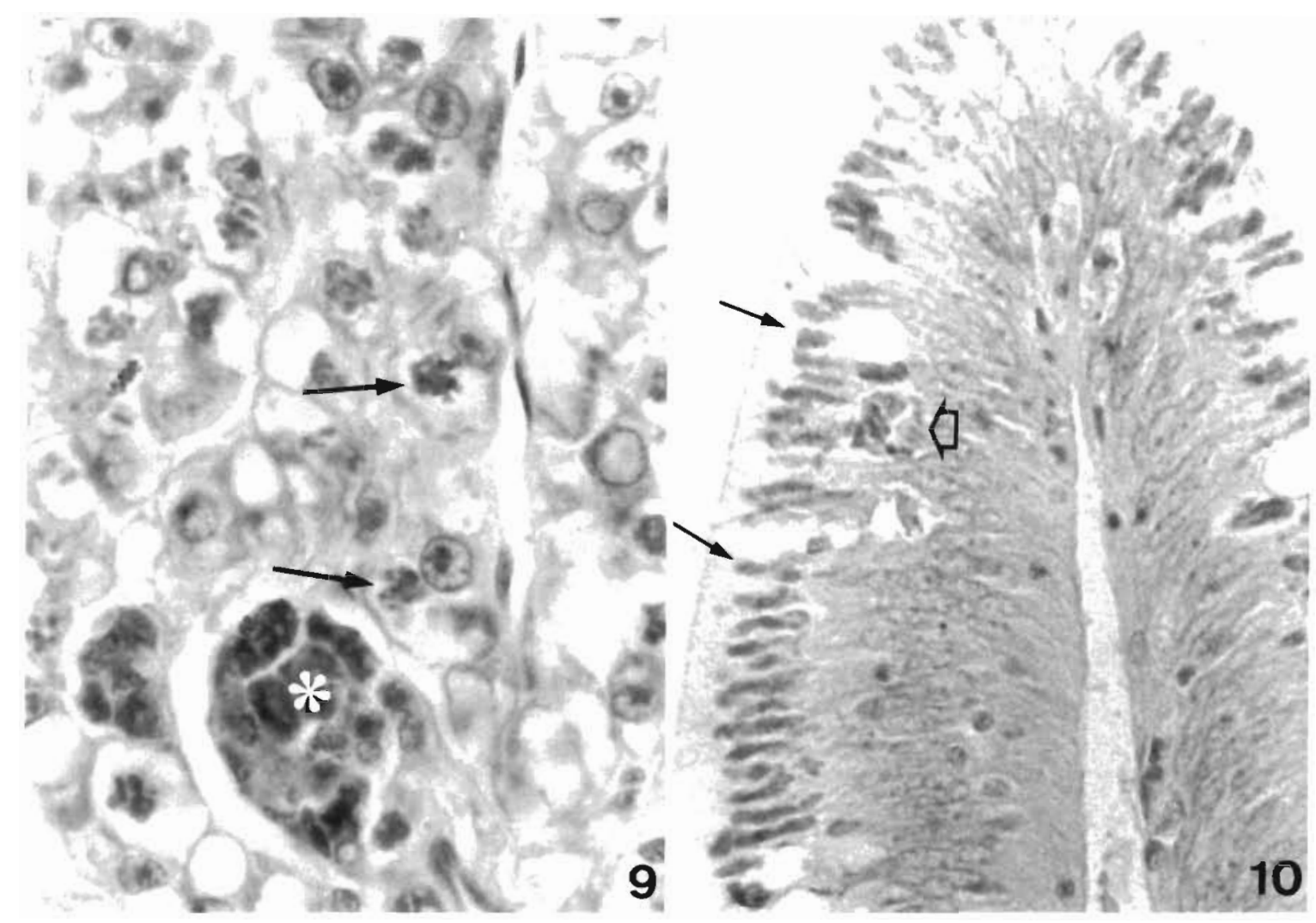

Figs. $9 \& 10$. Scophthalmus maximus. Fig. 9. Liver of affected turbot. Pigment-like material accumulates in the hepatocytes (arrow) and in macrophages (asterisk). H\&E, $\times 1180$. Fig. 10. Intestine of affected turbot. Note the presence of pigment in the apical cytoplasm of epithelial cells (arrows) and in macrophages (open arrow). H\&E, $\times 720$

these pigments. Special components of the granulomatous reactions are epithelioid cells and giant cells. Both cell types have frequently been described to be associated with inflammatory reactions of the granulomatous condition in fish (Richards et al. 1978, Timur et al. 1985, Pulsford \& Matthews 1991) and in granulomatous nodules experimentally induced in turbot (Balouet \& Baudin Laurencin 1986). Epithelioid cells are believed to be enlarged histiocytic cells which themselves stem from circulating monocytes. Giant cells differ from epithelioid cells in that they are multinucleate and show higher phagocytic capacity (Woolf 1986).

The epithelioid cells described in this paper have 1 very large nucleus which is often bi- or multilobed. This might be due to the nucleus going through mitosis with neither the daughter nuclei nor the cytoplasm being separated. The giant cells, scarce in the nodular lesions of turbot, show several highly pleomorphic nuclei. Giant cells are probably derived from epithelioid cells by the multilobed nucleus being completely separated into several nuclei. Thus epithelioid cells as well as giant cells can be regarded as polyploid. Polyploidy may indicate tumorous transformation of these cells in response to the accumulation of lipofuscin-like material. On the other hand, poliploidy may well be a cell strategy in order to increase the cell size and, in consequence, phagocytic capacity.

The black hyperpigmented areas located around the nodules or in isolated patches on the skin were superficial melanosis involving the epidermis, similar to that described in other fish species (Bogovski \& Bakai 1989, Okihiro et al. 1993). However, whether these lesions were hyperplastic reactions induced directly by the lipofuscin-like pigments or by secondary metabolic disorders is still unknown. The absence of neoplastic growth in any of the fish sampled indicates that these lesions were benign, although we cannot discount the possibility that a malignant transformation would occur with longer exposures.

Lipofuscins are pigments derived from lipids or lipoproteins which are at least partially oxidized. Under normal conditions, lipofuscins are endogenous pigments which accumulate in several organs with age and are yellowish-brown (Woolf 1986). However, depending on the original lipid and where the oxidation takes place, it can be a highly coloured product (Pearse 1985). Oxidized lipids are toxic for fish (Roberts 1989). 
Usually, these lipids are acid-fast, and in consequence are identified as ceroids. Ceroids are considered to be typical lipofuscins in an early stage of oxidation (Pearse 1985). Ceroid usually accumulates in the liver and in the spleen and kidney of fish fed with rancid lipids or which are vitamin E deficient (Smith 1979, Roald et al. 1981, Moccia et al. 1984); however, these authors do not mention accumulations of pigment in the intestine or nodules in the skin. The presence of the pigmented substances in the intestinal epithelium and macrophages of the lamina propria and submucosa of affected turbot may be an indication that lipofuscinlike pigments were included in the food. However, the low percentage of affected fish and the absence of these substances in the tissues of normal-looking turbot which shared the tanks with the turbot having skin nodules make that hypothesis unlikely, unless the normal-looking turbot were able to metabolize the lipofuscin-like pigments. Other possibilities are metabolic disorders or low levels of vitamin $E$ in the tissues. The presence of fatty liver in 'normal-looking' turbot is an indication that fish were fed a diet containing high levels of fats. As undigested lipid-rich substances are usually accumulated as lipofuscins (Goudie 1988), any metabolic disorder, e.g. in the lysosomic hydrolases of the intestinal epithelium, could make lipids difficult to digest and, in consequence, the lipids would accumulate in the fish tissues. Unfortunately, however, these considerations are merely speculative and the ultimate cause of this pathological problem has not yet been elucidated

Acknowledgements. This study was supported by grants AGF93-0769-CO2-02 and AGF94-1360-CO3-03 from the Comisión Interministerial de Ciencia y Tecnología (CICYT). We also thank Prof. Ramón Anadón for reading the manuscript and for valuable suggestions.

\section{LITERATURE CITED}

Balouet G, Baudin Laurencin F (1986) Granulomatous nodules in fish: an experimental assesment in rainbow trout, Salmo gairdneri Richardson, and turbot, Scophthalmus maximus (L.). J Fish Dis 9:417-429

Bogovski SP, Bakai YI (1989) Chromatoblastomas and related pigmented lesions in deepwater redfish, Sebastes mentella (Travin), from North Atlantic areas, especially the Irminger Sea. J Fish Dis 12:1-13

Fernández-Puentes C, Novoa B, Núñez S, Figueras AJ, Toranzo AE (1991) The turbot diseases in a Galician farm (Spain): one year study. EAS Spec Publ 14:97-98

Gabe M (1976) Histological techniques. Masson, Paris

Responsible Subject Editor: N. Peters, Hamburg, Germany
Goudie RB (1988) Molecular and cellular pathology of tissue damage. In: Anderson JR (ed) Mur's textbook of pathology. Edward Arnold, London, p 3.1-3.34

lshikawa T, Masahito P. Matsumoto J. Takayama S (1978) Morphologic and biochemical characterization of erythrophoromas in goldfish (Cardssius auratus). J Natl Cancer Inst 61:1461-1470

Lamas J, Anadón R, Devesa S, Toranzo AE (1990) Visceral neoplasia and epidermal papillomas in cultured turbot Scophthalmus maximus. Dis aquat Org 8:179-187

Moccia RD, Hung SSO, Slinger SJ, Ferguson HW (1984) Effect of oxidized fish oil, vitamin E and ethoxyquin on the histopathology and haematology of rainbow trout, Salmo gairdneri Richardson. J Fish Dis 7:269-282

Novoa B, Figueras A, Ledo A, Barja JL, Toranzo AE (1991) Incidence of birnavirus in cultured turbot (Scophthalmus maximus L.) in Northwest Spain. FHS/AFS Newsl 19(2): $2-3$

Okihiro MS, Whipple JA, Groff JM, Hinton DE (1993) Chromatophoromas and chromatophore hyperplasia in Pacific rockfish (Sebastes spp.). Cancer Res 53:1761-1769

Pearse AGE (1985) Histochemistry, theoretical and applied, Vol II. Churchill Livingstone, Edinburgh.

Pulsford A, Matthews RA (1991) Macrophages and giant cells assocrated with a microsporidian parasite causing liquefaction of the skeletal muscle of the Norway pout, Trisopterus esmarkii (Nilsson). J Fish Dis 14:67-78

Richards RH, Holliman A, Helgason S (1978) Exophiala salmonis infection in Atlantic salmon, Salmo salar L. J Fish Dis 1:357-368

Roald SO, Armstrong D, Landsverk T (1981) Histochemical, fluorescent and electron microscopical appearance of hepatocellular ceroidosis in the Atlantic salmon Salmo salar L. J Fish Dis 4:1-14

Roberts RJ (1989) The nutritional pathology of teleosts. In: Roberts RJ (ed) Fish pathology. Ballère Tindall, London, p $337-362$

Smith CE (1979) The prevention of liver lipoid degeneration (ceroidosis) and microcytic anaemia in rainbow trout Salmo gairdneri Richardson fed rancid diets: a preliminary report. J Fish Dis 2:429-437

Thoesen JC (1994) Suggested procedures for the detection and identification of certain finfish and shellfish pathogens, 4 th edn, Version 1. Fish Health Section, American Fisheries Society, Maryland

Timur M, Timur G, Roberts RJ (1985) Moderation of the experimental carrageenin granuloma in the plaice, Pleuronectes platessa L., by reduction in temperature. J Fish Dis 8:523-527

Toranzo AE, Barja JL, Devesa S (1994) An overview of the main infectious problems in cultured turbot: present status and necessities. In: Lavens P, Remmerswall R (eds) Turbot culture: problems and prospects. EAS Spec Publ 22, EAS Gent, Belgium

Toranzo AE, Novoa B, Romalde JL, Núnez S, Devesa $S$, Marin̄o E, Silva R, Martínez E, Figueras A, Barja JL (1993) Microflora associated with healthy and diseased turbot (Scophthalmus maximus) from three farms in northwest Spain. Aquaculture 114:189-202

Woolf $N$ (1986) Cell, tissue and disease: the basis of pathology. Ballière Tindall, London

Manuscript first received: March 19, 1995

Revised version accepted: August 30, 1995 